\title{
The Construction and Improvement of Modern Public Sports Service System in Ethnic Minority Region
}

\author{
Zongjie Liu ${ }^{1, a}$ Hongyan $X u^{1, b}$ \\ ${ }^{1}$ Xijing University, Chang'an District, Xi'an, Shaanxi, China, 710123 \\ ${ }^{a}$ email, bemail,
}

Keywords: Construction, Improvement, Modern Public Sports Service System, Minority Region

\begin{abstract}
The development of minority areas is lagging behind affected by the regional economic, education and culture, ethnic people's living standards and development gap between the urban and the rural is huge, uneven development of mass sports, relative lack of effective supply of fitness services, the conditions of accessing to basic mass sports service environment have practical difference. For this reason, the minority region national fitness service system should improve the organization and management body, form diversified financing channels, organize feature race and sports activities and form a national fitness project on the basis of the national culture and the human geography. This research is aimed at establishing harmonious ethnic relations with equality, unity, mutual assistance to meet the growing needs of all ethnic mass sports and improve the physical health of the people of all ethnic groups.
\end{abstract}

\section{Introduction}

In recent years, with the establishment of service-oriented government targets, public service has become one of the important functions of our government, building a sound public service system has become an important task for our government transformation. Public sports service system as an important part of the public service system, has been attached great importance to the party and the state. July 11, 2012 the State Council issued the "national basic public service system," second five "plan" will be mass sports included in the basic public service system category. "Sports Five-Year Plan" clearly states that to establish and improve in line with national conditions, more complete, covering urban and rural areas, sustainable public sports service system, focusing on improving the service level of public sports." Our country is still in the primary stage of socialism, in different regions economic and social development is uneven, with different physical needs of the residents, especially in minority areas, therefore, the construction of public sports service system in minority areas has a different development path elsewhere. How to build and improve public sports service system in minority areas, in building a moderately prosperous society and building a sports power today, it is particularly urgent.

\section{The Concept of Public Sports Services}

For time now, the name of "public service sport" and "sport public service" varies, but according to the 2011 publication of "sports development" second five "plan" does not appear in "sports public service," this reference and "public sports service" as a keyword appeared a total of 16 times, while in 2011 the director of National Sports Conference of General Administration Liu Peng use the "public sports service", it is visible that " public sports service" is the official statement. This source of our science, education, culture, health and body for a long time and become China's five major utilities. Public sports services, public health services, science and technology public service call has been widely recognized.

Public sports service system can be both broad and narrow sense defined narrowly public sports service system that is the content of public sports service system, including the national physique monitoring service, Olympic Glorious services, sports guidance services, sports information services, sports services and sports elements of the broad public sports service system comprises the supply of public sports service system, the system of needs, content system, security system, 
evaluation system and operational mechanism; facilities services section.

\section{The Realistic Background of Modern Public Sports Service System in Ethnic Minority Areas}

Construction of regional public sports service system must follow the law and public service pay close attention to the region's own characteristics, in the public interest objective, scientific constructed according to the regional geographic, economic and cultural characteristics. Unlike ethnic-minority areas of economic, social and cultural background of the population in other regions, therefore, the construction of public sports service system, must take into account the special nature of minority areas, in line with social development in ethnic minority areas of economic conditions, in order to better meet the minority national sports needs of residents and protect their sports interests.

In the socio-cultural composition, ethnic minorities have their own traditional culture and lifestyle and way of public cultural services in minority areas should be adapted to the local people's traditional culture, habits and religious beliefs. Public sports service system as an integral part of the public cultural service system must meet the needs of local residents of public sports, otherwise easily lead to low public sports service supply efficiency. The minority in the long history of the development process of forming a colorful, distinctive sports culture. On the one hand, this minority traditional sports culture as a public sports service system provides a number of resources to build sports laid a good foundation. In addition, ethnic minority areas with larger populations of all ethnic groups are different socio-economic backgrounds form different sports demand, demographic composition determines the Public Sports Service content and the way of supplying the diversity and complexity.

Relatively restraining the regional economy, education, cultural development by minority areas nationwide fitness activities faced with an imbalance between urban and rural areas; unbalanced participation in sports activities groups; participation in physical activity levels of imbalance; sports facilities construction and funding imbalances the impact of supply shortages and increased demand for supply and demand serious, serious shortage of sports funds and capital investment, the number of facilities the venue is too small, large and medium-sized shortage of public sports facilities, the construction area and site area accounts imbalance, small towns speed slow, fitness networks and organizations and urban service system there are significant gaps in comparison, the overall level of sports development in the construction services sector is lagging behind. Resulting in urban and rural residents to participate in sports activities, mainly in parks, streets Hong Mei, grasslands, rivers, forests, mountain exercise, form in most of the options exercise alone or with friends and acquaintances, family, fitness facilities have a fixed activity stations (room) relatively few activities are more spontaneous formation of organizations, which are mostly individual fitness programs are free and strong, or investment in the engagement process is not high, or which carry out sports activities, ethnic festivals, festivals production and use of the natural environment are involved in most sports schedule sports consumption remained at the physical level of consumption, the proportion of labor used in consumer spending is low, publicity fitness activities, counseling, skills transfer, equipment leasing, brokerage and other activities relative lack of products and services, effective supply relatively scarce. Coupled with the rural township (town) financial difficulty funding for sports is very scarce, investment is almost zero, which guarantees access to basic public services, sports fitness service system, $80 \%$ of the township (town) funding for sports is only temporary East to fight the West Minato, local finance and no special pay, benefit farmers and herdsmen in the interests of the sports service, to establish the necessary state, county (township) town (village) of mass sports organization is non-existent, to protect farmers and herdsmen exercise venue poor facilities, sports the role of the competent authorities, the administrative authority and use of funds is very limited, resulting in ethnic minority areas to build fitness service system difficult. 


\section{The Construction Content of Modern Public Sports Service System in Ethnic Minority Areas}

Improve Organization and Management System. Fitness is a national advocacy and conduct involving the whole society, the whole nation, a national policy of the nation, there must be strong organizational leadership and scientific management. Which establish and improve the fitness organizations would be a necessary condition for minority regions nationwide fitness service system. To this end, five National Fitness Program by the government departments, religious things, mass organizations and social groups responsible for the composition of the leading group of 6 basic outline of the minority areas should be established and county, township fitness mass organization whose mission take responsibility for the development of local mass sports will mass sports promotion by the department work for the government work, by the sports department full-time into the whole society, a common cause of the whole nation, to strengthen the masses of sports leadership and leadership efforts. And sports associations, supplemented by active community contact, township mass sports organization, to form a sports fitness the main line to the street, rural site based, schools, communities, villages and towns as the key to social sports instructor for the backbone to the principle of voluntary participation in profit as the main body, in different sectors of the population to participate for the characteristics of society into the direction of mass sports organization, and ultimately achieve the city and county echoes, independent, upper and lower communication, horizontal linkages, wide coverage, inclusive of the amount of mass sports organization network to form a government of minority people take the overall level of physical health, the primary responsibility of the negative pattern.

Form Diversified Financing Channels. Minority Region National Fitness Service System as a social phenomenon. Currently the national minority areas and developed areas compared to the level of economic and social development to the National Exercise and the supporting force is weak. To implement this goal, it is necessary to form a government investment-led, all sectors of society to complement the diversified financing channels, focusing on the construction of venues and facilities. Establishment of infrastructure into the government social development plans at all levels of minority areas major sports venues and facilities; the establishment of the State Sports General Administration included in underdeveloped areas and counties (state), local financial township (town) levels of regional sports facilities, venues, investment maintenance and other construction projects; the establishment of the issue sports lottery, sports lottery computer for stadium construction and investment in the National health service system; encourage social investment, real estate developers to increase development zone residential areas of Public Stadium facilities investment; development of communities, businesses, schools, villages and towns exercise venues, facilities and equipment utilization, achieve a City, a gymnasium, a county center (fitness center: with indoor gymnasium and outdoor fitness course), a village (community) a station (sports cultural centers: with a hardened standard basketball courts, a fitness path), a village of a (social sports instructor), in order to establish the necessary material foundation for the ethnic minority areas nationwide fitness activities.

Organize Feature Race and Sports Activities. To carry out mass sports activities and sports events are organized by specialties to achieve universal health service system in the main content. Such activities can rely on the unique advantages of minority areas of culture and geography. Held across the region, city (county), township (town) and village and other local large mass sports activities at all levels, these activities can rely on national holidays, festivals, Culture and Tourism Festival and New Year's Day, May, November and other holidays once a year to implement the National fitness week, once a month the National fitness day, and adhere to a daily participation in morning (evening) fitness to practice points to the diversity of small, often dispersed purposes, it can absorb such activities different nationalities, different classes, different people of the region have a strong interest in all kinds of sports activities, and actively guide the masses to carry out scientific, healthy and civilized fitness activities, healthy and progressive occupation of mass sports fitness activities and cultural fronts. 
Provide Regulations and Policies Assistance and Establish Assess Recognition Mechanisms. Construction inseparable mass sports policies and regulations aid Minority Region National Fitness Service System, and to promote its scientific assessments recognition work. Use of various forms of propaganda and means of newspapers, radio, television and other fruitful propaganda and agitation, to open up or expand the fitness aspect of special columns, selected boutique fitness project, the formation of fitness activities in recognition of the assessment mechanism to promote the recognition of the assessment system institutionalized, standardized and scientific. Create a group of ethnic, institutional, exemplary, having driven brand of radiation effective fitness activities. Fitness formed in ethnic minority areas of public opinion, highlighting the social value system of national fitness service system, to make fitness work is the material basis of ideological and moral qualities and scientific and cultural qualities of fitness work is the main content of socialist material civilization, fitness is an important symbol of social progress and the extent of human civilization, attract the masses to everyone involved in national fitness activities, so that the masses diversified fitness system truly represents the development requirements of advanced productive forces; make connotation fitness system truly reflects the orientation of advanced culture; to make real national fitness system for the general public on behalf of the fundamental interests of the masses.

\section{Conclusion}

The development of minority areas is lagging behind affected by the regional economic, education and culture, ethnic people's living standards and development gap between the urban and the rural is huge, uneven development of mass sports, relative lack of effective supply of fitness services, the conditions of accessing to basic mass sports service environment have practical difference. It has to obtain the attention, support, investment funds of the nation and local government for fitness service system, establish a diversified investment system and fully mobilize the community and personal investment to ensure fitness service system, promote fitness service business level of industrial development in ethnic minority areas.

\section{Acknowledgements}

Fund Project: Shaanxi Provincial Department of Education Special Research Programs (Item Number: 16JK2226).

\section{References}

[1] Jia Xinzhang, Li Jingyuan. Sports Culture Guide, Vol. 6 (2014) No 53, p.25-26

[2] Peng Sue, Wang Yunhui, Wang Qunyong. NPC study, Vol. 12 (2015) No 27, p.74-76

[3] Hou XuSi. Sports Culture Guide, Vol. 30 (2014) No 19, p.144-145

[4] Wang Kuailiang. China Sport Science and Technology, Vol. 29 (2008) No 27, p.21-23

[5] Zhang Gongxu, Sun Jing. Xi'an Institute of Physical Education, Vol. 8 (2013) No 27, p.57-60 